\title{
Measurement of Proton Autoneutralization Potential
}

\author{
Manuel Garcia
}

This paper was prepared for the Proceedings of the 5 th Topical Conference en High Temperature Plasnı Diagnostics Granlibakken Resort at Lake Tahoe, CA

September 36-20, 1984

\section{September 1984}

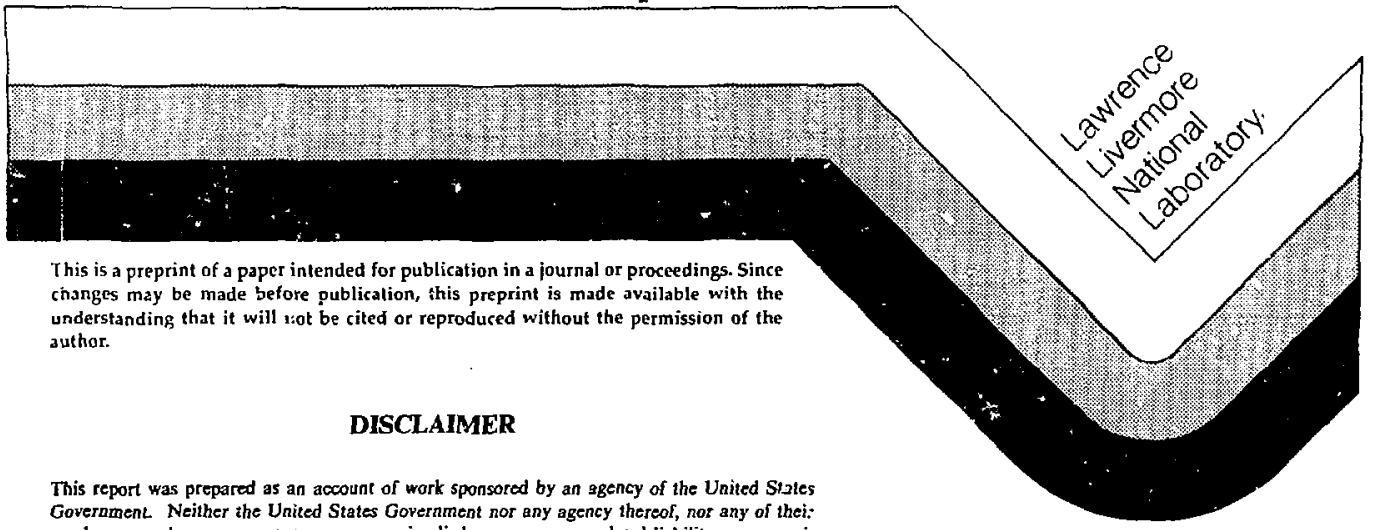
Government Neither the United States Government nor any agency thereol, not any of the: bility for the accuracy, completeness, or usefulness of any infermation, ayparatus, product, or process disciosed, or represents that its use would not infringe privately owned rights. Reference heiein to any specific commercial product, process, or service by trade name, trademark, manufacturer, or otherwise does not necessarily consitute or imply its endorsement, recommendation, or favoring by the United States Government or any agency thereof. The views and opinions of authors expressed herein do not necessarily state or reflect those of the United States Government or any agency thereof. 


\title{
Measurement of Proton Autoneutralization Potential
}

\author{
Manuel Garcia \\ Lawence Linermore National Laboratory, Iniversity of Californin, P.O. Box 808, Livermore. \\ California 94550
}

A proton space charge having multi-MeV kinetic energy was injected through a thin ground plane to extract electrons and produce a time-dependent autoneutralization space potential. An electron-emitting floating potential resistive divider was used to measure the space potential during $20 \mathrm{~ns}$ of the proton current pulse. During this time, proton kinetic energy fell from 10.6 M.aV to $8.5 \mathrm{MeV}$ and thus the space potential (taken as $1.09 \times$ the floating potential) fell from $5.8 \mathrm{kV}$ to $4.6 \mathrm{kV}$.

\section{INTRODUCTION}

The measurement of multi-megavolt-potential time histories with narosecond resolution is a formidable task lacing researchers in pulsed power. This paper describes an experiment that exploits the autoneutralization phenomenon' and utilizes simple electric-probe technology ${ }^{2}$ to accomplish this task. First, however, we review the autoneutralization model and develop an appropriate probe theory for designing probes and interpreting data.

\section{AUTONEUTRALIZATION MODEL}

Figure 1 shows the one-dimensional auioneutralization model formulated by Humphries $\mathrm{ct} a l .{ }^{1}$ on which this experiment is based. When a proton space charge $\left(n_{+} \mathrm{cm}^{-3}\right)$ having multi-MeV kinetic ( nergy $\left(I_{-k}\right)$ erupts through a thin ground plane it can extract a compensating electron charge $\left(n_{\mathrm{v}}=n_{+}\right)$ and current density $\left(j_{\mathrm{v}}=-j_{+}\right)$and produce a neutrai inoving $\left(\left\langle v_{v}\right)=v_{+}\right)$proton-electron plasma; this plasma has a positive space potential $V_{\mathrm{S}}=\left(m_{\mathrm{e}} / m_{+}\right) E_{\mathrm{K}}$ above ground. Such ore-dimensional accele:ation of cold electrons requires one-half of an ion kinetic Debye length $\left(h_{\mathrm{DL}}=\sqrt{E_{\mathrm{K}}}\right.$ voits $/ n_{+} \mathrm{cm} \cdot \mathrm{j}$ $\mathrm{cm})$, which is based on the proton kinetic energy and density. Within the distance / plane, the space potential and average electron velocity exhibit a damped spatial oscillation. Electrons exiting the acceleration zone have average kinetic energy $V_{\mathrm{S}}=\left(m_{\mathrm{d}} / m_{+}\right) E_{\mathrm{K}}$, average velocity $\left(z_{\mathrm{p}}\right)=v_{+}$. and a temperature $T_{1}=0.043 V_{S}$ (volts), which represents a three-dimensional randomization of the 
one-dimensional velocity spread accumulated during acceleration. Beyond $h_{\mathrm{Dl}} / 2$, the ratio of proton piasma space potential to average proton kinetic energy is

$$
\frac{V_{\mathrm{s}}}{E_{\mathrm{K}}}=\frac{m_{\mathrm{v}}}{m_{\mathrm{i}}}=\frac{1}{1836.1}=\frac{0.545 \mathrm{kV} \text { of space potential }}{\mathrm{MeV} \text { of kinetic energy }} .
$$

An electric probe sampling downstream of the acceleratior zone should see a plasma with the following properties:

- $E_{\mathrm{K}}$ kinetic energy, $\mathrm{V}$.

- $j_{+}=\mathrm{c}^{\prime}, v_{+}$, proton current density, A/ $\mathrm{cm}^{2}$,

- $v_{*}={ }_{1} 2 \mathrm{e}_{\mathrm{k}} / m_{+}$, proton velocity unchanged by autoneutralization as $m_{+} / \mathrm{m}_{+} \ll 1, \mathrm{~cm} / \mathrm{s}$.

- $n_{\mathrm{c}}=n_{1}, \mathrm{~cm}^{3}$.

- $(n)=\mathrm{i}, \mathrm{cm} / \mathrm{s}$,

- $V_{\xi}=\left(m_{1}, m\right) E_{k}, V$.

- $T_{\mathrm{a}}=0.043 \mathrm{~V}_{\mathrm{s}}, \mathrm{r}$.

\section{EXPERIMENT}

\section{Proton current density pulse}

Figure 2 shows the current-density $i_{+}$and kinetic-energ; $E_{\mathrm{K}}$ time histories (curves 2 and 3 , respectively) of the driving proton pulse at the floating WP (wire probe) location. The values of $E_{\mathrm{K}}$ are labeled on curve 3, and the peak $i_{+}$value of $4.2 \mathrm{~A} / \mathrm{cm}^{2}$ occurs at $10.6 \mathrm{MeV}$, which corresponds to $507 \mathrm{~V}$ on Fig. 2. The $E_{\mathrm{K}}(t)$ and $j_{+}(t)$ scalings used for Fig. 2 are discussed in detail in Data and Interpretatiom below. The proton kinetic energy drops from is $\mathrm{MeV}$ to below $6 \mathrm{MeV}$ in $0.1 \mu \mathrm{s}$. The proton current density pulse has a FWHM (full width at half-maximum) of 18 ns and a total proton current of $166 \mathrm{~A}$ after the ground mesh. Table I lists its spatial properties.

\section{Drift tube}

The stainless steei drift tube is $70.7 \mathrm{~cm}$ long and has an i.4. of $29.2 \mathrm{~cm}$ and $0 . d$. of $30.5 \mathrm{~cm}$. The entrance collimator is $4.8 \mathrm{~cm}$ in diameter and is covered by a mesh (92.2\% open area) made of $10-\mathrm{mi}$ diameter steel wire on a $6.35-\mathrm{mm}(0.25 \mathrm{in}$ ) grid (Fig. 3). The "nose" of the current pulse arrives at the endwall $(70.7 \mathrm{~cm})$ as the "tail" leaves the mesh. The dift tube sidewall is always outside the diameter of the current pulse. A vacuum of $10^{-6}$ Torr was maintained inside the drift tube. 


\section{Wire probe}

The WP (Fig. 4) consists of a 6.35 -mm-diameter $(0.25 \mathrm{in}$.) brass rod extending into the plasma from a reramic high-voltage insulator that is well outside the plasma diameter. The broadside area of this brass rod exposed to the vlasma is $2.41 \mathrm{~cm}^{2}$. The rod connects through the insulator to $2050 \Omega$ of probe impedance and $50 \Omega$ of signal cable impedance, which gives a total impedance of $2100 \Omega$. The probe impedance is uistributed over ten $2-W$ carbon resistors connected in series by short brass rods of equal dianeter $(\mathrm{c} .7 \mathrm{~cm})$ and potted inside a $3.8-\mathrm{cm}$-diameter $(1.5 \mathrm{in.})$ tube. The entire coaxial impedance structure is $30.5 \mathrm{~cm}$ (12 in.) long and has an estimated inductance of $64.4 \mathrm{nH}$ and a measured capacitance of $30 \mathrm{pF}$. Inductance effects are negligible in this experiment. The response time of this probe is estimated to be $1.5 \mathrm{~ns}$. An elementary circuit model (having a step functior space potential connected 10 ground through the $2050-\Omega$ probe in series with both the $30-\mathrm{pF}$ and $50-\Omega$ signal line in parallel) produces a probe impulse response ( $c$-folding) risetime of $1.46 \mathrm{~ns}$. Measured WP response to pulsed electron (Febetron) irradiation of the probe tip is consistent with this model. This probe can easily track space potential variations on a 5 -ns time scale.

\section{PROBE THEORY}

The $W \Gamma$ is an electron-emitting floating-potential probe with a sheath drop $\left(V_{S}-V_{\mathrm{E}}\right)$, which is about $10 \%$ of either the space or floating potential. ${ }^{2}$ The floating potential $V_{\mathrm{E}}$ is that cxpected for a perfectly atsorbing probe having infinite impedance. The measured probe potential $v_{1}$ is the sum of the "forating" and "emission" terms discussed below.

Because the kinetic particle fluxes $n_{-} u_{\perp}$ and $n_{c}\left(z_{\mathrm{e}}\right)$ are equal, this probe senses space potential $v_{S}$ by draining a current less than the net imbalance in thermal currents swept into the probe sheath. The electron saturation current is up to four times greater than in station iry situations because the plasma is swept inlo the probe at much higher speed than by thermal diffusion. Lower-impedance higher-current probes can float near $V_{s}$. Although neutralized, the kinetic particle fiuxes do register an effect on the probe. Froton impacts on the brass tip eject electrons and contribute a positive enhancement to the space potential signal. This effect can easily be modeled and removed from the data or eliminated by a more elaborate tip construction. A hollow' Faraday-cage probe electrode that traps ejected electrons can be constructed using a "proton-thick" cone whose "proton-thin" base foil faces tho incoming plaima. 


\section{Floating potential}

Because $m_{+} / m_{\mathrm{e}} \gg T_{+} / T_{\mathrm{c}} \gg 1$ for this autoneutralized plasma, the proton number density and thermal velocity are negligibly affected by the electron-retarding sheath drop $\Delta V=V_{S}-V_{5}$. Equating the thermal current densities at the probe surface and canceling common factors produces a relationship between foating potential and space potential| ${ }^{2-5}$ :

$$
\begin{aligned}
& \sqrt{\frac{T_{\mathrm{v}}}{m_{\mathrm{e}}}} \exp \left(\frac{-\mathrm{d} V}{T_{\mathrm{e}}}\right)=\sqrt{\frac{T_{+}}{m_{+}}}, \\
& V_{\mathrm{E}}=V_{\mathrm{S}}+0.5 T_{\mathrm{e}} \ln \left(\frac{T_{+} m_{\mathrm{e}}}{T_{\mathrm{c}} m_{+}}\right), \\
& V_{\mathrm{F}}=1+0.0215 \ln \left(\frac{T_{+} m_{\mathrm{e}}}{\frac{T_{\mathrm{t}} m_{+}}{+}}\right) .
\end{aligned}
$$

The value of $V_{E} / V_{5}$ is 1 when proton and electron thernal speeds are equal and is 0.84 for an isothermal plasma. The midpoint of this range is 0.92 , occurring at $T_{+} / T{ }^{*}=40$, and implies a ratio of proton kinetic energy to floating potential of

$$
\frac{E_{\mathrm{k}}}{V_{\mathrm{k}}}=1.09 \frac{m_{+}}{m_{\mathrm{s}}}=1996 .
$$

\section{Probe clirrent}

The maximum current that a plasma voltage probe can draw is the electron thermal current swept into the probe sheath. If the probe draws more current, the sheath expands into the plasma, and the probe potential deviates below the floating potential. in the case of the autoneutralization floating probe,

$$
I_{\Gamma}=\frac{V_{\mathrm{E}}}{R} \leq 0.234 j_{+} A_{\Gamma}
$$

where $R$ is the total $\mathrm{im}_{1} x$ dance to ground. The electron thermal current density swept into the probe sheath is four times that of a thermally equivalent stationary plasma. As the plasma velocity is normal to the probe area and much higher than any thermal speed, electrons diffusing in any of the four 
directions parallel or perpendicular to this area are swept into the sheath. The electron thermal curre!t

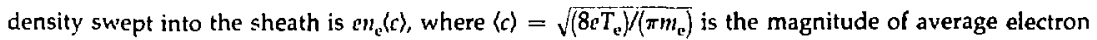
thermal velocity with $T_{e}$ in volts. Substituting $T_{e}=0.043 V_{S}$ in $\langle c\rangle$ produces

$$
\cot _{*}\langle c\rangle=0.234 \%
$$

as the limiting current density that a floating autoneutralization probe can draw.

The condition $I_{\Gamma} \leq 0.234 j_{\mathrm{d}} A_{\Gamma}$ is equivalent to $V_{\mathrm{E}} \leq 0.234 \mathrm{~V}$, for a perfectly absorbing probe. This condition is most closely met in the experiment between 30 and $50 \mathrm{~ns}$, when $j_{-}$is near its peak of $4.2 \mathrm{~A} / \mathrm{cm}^{2}$. Figure 2 shows $V_{\mathrm{E}} / 42$ (curve 3 ) and $V_{i} / 42$ (curve 2 ).

\section{Electron emission model}

To extract the time history of the autoneutralization potential from the probe signal in this experiment, a time-tependent model of preton impact-induced electron emission had to be invoked. This model relies on published electron kinetic ejection data.

Let 7 : represent the number of electrons ejected into $4 \pi$ per proton impact. McDaniel $\left.\right|^{6}$ showed that proton $\gamma_{\text {i }}$ 's $E_{K} \leq 2 \mathrm{MeV}$ into metals where $\gamma_{i}$ is -2 at $E_{\mathrm{K}}=0.5 \mathrm{MeV}$ and $\gamma_{\text {, is }} \sim 0.5$ at $E_{\mathrm{K}}=2 \mathrm{MeV} ; \gamma_{\text {, }}$ scales as $1 / E_{\mathrm{K}}$ and ext $t_{1}$ ) lates naturally to $\sim 0.1$ at $10 \mathrm{MeV}$. For this experiment, $\gamma_{t}$ is modeled as $\gamma_{t}=$ $1.1 / E_{\mathrm{K}}-\mathrm{MeV}$, and the time-dependent electron-emission current density from the probe is $\gamma_{,} j_{+}$. The peak emission-current density of $0.44 \mathrm{~A} / \mathrm{cm}^{2}$ is reached when $E_{\mathrm{K}}=10.6 \mathrm{MeV}$ and $j_{+}=4.2 \mathrm{~A} / \mathrm{cm}^{2}$.

An electron-emitting floating-potential probe should see a total probe potential of

$$
V_{1}=V_{\text {LoHlitiwi }}=\left(V_{\mathrm{t}}=0.92 V_{\mathrm{s}}\right)+\left(V_{1}=j_{+} A_{\Gamma} R\right) \gamma_{1}
$$

as long as plasma exists in the vicinity of the probe tip. $V_{E}$ is the floating potential expected for a perfectly absorbing probe, and $V_{i}$ is the high-impedance Faraday-cup equivalent of the proton current density. Curves 2, 3, and 4 in Fig. 2 show $V_{1}(t), V_{\mathrm{E}}(t)$, and $V_{\text {colleclive }}(t)$, respectively. 


\section{DATA AND INTERPRETATION}

\section{Data}

Figure 2 displays the voltage probe data, the time histories of the proton pulse kinetic energy and current density, and the probe voltage enhancement resulting from electron kinetic ejection. The $x$-axis gives time in nanoseconds, and the $y$-axis gives volts into the $50-\Omega$ signal cable (which equals the probe voltage divided by 42 ).

Curve $1\left(V_{\mathrm{p}} / 42\right)$ is the measured probe voltage, which peaked at $181 \mathrm{~V}$.

Curve $2\left(V_{1}=j_{+} A_{\mathrm{f}} R\right) / 42$ is the probe voltage equivalent of the proton current density. The peak of $507 \mathrm{~V}$ occurred when $E_{\mathrm{K}}=10.6 \mathrm{MeV}$.

Curve $3\left(V_{\mathrm{L}} / 42\right)$ is the autoneutralization floating potential for a perfectly absorbing infiniteimpedance probe. This curve is a scaling of proton kinetic energy vs time, and several $E_{\mathrm{x}}(t)$ values are noted.

Curve $4\left(V_{1}+\gamma_{1}, V_{1}\right) / 42$ is the sum of curve 3 and the actual electron-emission voltage enhancement.

\section{Interpretation}

When the ion kinetic Debye lengih $h_{\mathrm{DI}}>70.7 \mathrm{~cm}$ (curve $1=$ curve 2 ), the proton current density $j .<0.84 \mathrm{~A} / \mathrm{cm}^{2}$, no plasma exists on the scale of the drift tube, and the voltage probe acts as a highimpedance Faraday cup that collects unneutralized $j_{+}$through area $A_{p}$ :

$$
V_{1}=V_{1}\left(1+\gamma_{1}\right)
$$

The probe data $V_{\mathrm{F}}(t)$ tracks $j_{+}(t)$, and electron-emission effects are small.

When the ion kinetic Debye length $h_{\mathrm{DI}}<70.7 \mathrm{~cm}$ (curve $1=$ curve 4 ), the proton current density $i_{i}>0.84 \mathrm{~A} / \mathrm{cm}^{2}$, and plasma phenomena are encountered, then between 30 and 50 is, the proton current density is near its peak of $4.2 \mathrm{~A} / \mathrm{cm}^{2}, h_{\mathrm{D} I} / 2$ is $\sim 15 \mathrm{~cm}, v_{+}$is $-4.4 \times 10^{9} \mathrm{~cm} / \mathrm{s}$, $n_{i} \leq 5.9 \times 10^{9} / \mathrm{cm}^{3}, T_{\mathrm{e}} \leq 248 \mathrm{~V}$, and the Debye length $h_{\mathrm{D}}$ (based on $T_{\mathrm{e}}$ ) is $\sim 0.15 \mathrm{~cm}$. During this interval, the probe voltage $V_{F}$ drops from $7.6 \mathrm{kV}$ to $5.0 \mathrm{kV}$ while the floating potential $V_{\mathrm{E}}$ drops from $5.3 \mathrm{kV}$ to $4.2 \mathrm{kV}$. The maximum electron-emission vitage enhancement $\gamma_{t} V_{j}$ is $2.3 \mathrm{kV}$ or $44 \%$ of the floating potential. The electron emission part of the signal is easily removed, and the remaining 
floating jotential signal is interpreted as a measured time history of diminishing autoneutralization space potential to within $10 \%$. This precision is an insensitive function of the uncertainty in $T_{+} / T_{\mathrm{e}}$. For $1 \leq T_{+} / T_{\mathrm{c}} \leq m_{+} / m_{\mathrm{c}}=1836.1$,

$$
\left(V_{r}-\gamma, V_{1}\right)=V_{E}=(0.92 \pm 0.08) V_{S}
$$

The floating-probe data between 30 and $50 \mathrm{~ns}$ can be interpreted as a $10 \%,<5$-ns-resolution measurement of proton space charge kinetic energy in the $10-\mathrm{MeV}$ range dropping at a rate of $0.1 \mathrm{MeV} / \mathrm{ns}$.

\section{CONCLUSION}

A $4.2-\mathrm{A} / \mathrm{cm}^{2}, 18-\mathrm{ns}$ FWHM proton current pulse with $10.6 \mathrm{MeV}$ kinetic energy at the current peak and with $8.5 \mathrm{MeV}$ kinetic energy $20 \mathrm{~ns}$ later was injected through a ground plane into a $70.7-\mathrm{cm}-\mathrm{long}$ drift tube to produce a time-dependent autoneutralization space potential. A 2.1-k 2, 42:1 voltagedividing floating-potential probe was used to track this space potential within $10 \%$, once the effect of proton-impact-induced electron kinetic ejection was removed. During 20 ns of plasma history, the space potential, taken as 1.09 times the floating potential, fell from $5.8 \mathrm{kV}$ to $4.6 \mathrm{kV}$, as expected from

$$
\frac{V_{5}}{E_{\mathrm{K}}}=\frac{m_{v}}{m_{.}}=\frac{1}{1836.1}=\frac{0.545 \mathrm{kV} \text { of space potential }}{\mathrm{MeV} \text { of kinetic energy }} .
$$

\section{ACKNOWLEDGMENTS}

Jim Leppien and Larry Wiley were stimulating collahorators and shared the experimental fun, Chuck Jones and Bill Olson provided low vacuum and solid engineering, Brent Davis and Edna Martinez provided clear signal paths, and Jim Morgan opened the corral gate to let us run.

This work was performed at Lawrence Livermore National Laboratory under the auspices of the U.S. Department of Energy under Contract No. W-7405-Eng-48.

\section{REFERENCES}

'S. Humpluries, Jr., T. R. Lockner, J. W. Poukey, and J. P. Quintenz, Phys. Rev. Letts, 46, 995 (1981).

2F. F. Chen, "Electric Probes," in Plasma Dingnosti Techniques, R. H. Huddlestone and S. L. Leonard, Eds. (Academic Press, New York, 1965), Chapter 4. 
${ }^{3}$ M. Garcia, A Rezicul of Intense Ion Berm Propagntion with a View toward Measuring lon Energy, Lawrence Livermore National Laboratory, Ljvermore, CA, UCID-19692 (1982). Available from M. Garcia, L-43, LLNL, P.O. Box 808, Livermore, CA 94550.

${ }^{+}$J. D. Swift and M. J. R. Schwar, Electric Probes for Plnsma Dingnostics (American Elsevier, New York, 1969).

${ }^{5}$ P. M. Chung, L. Talbot, and K. Touryan, Electric Probes in Stationary and Flowing Plasma: Theory and Applicntions (Springer-Verlag, New York, 1975).

${ }^{\circ}$ E. W. McDaniel, Collisionnl Phenumcua in lonized Gascs (J. Wiley \& Sons, Inc., New York, 1964), p. 645.

TABLE I. Spatial properties of the proton current density pulse, $j_{+}$.

\begin{tabular}{lccc}
\hline \hline Location & $\begin{array}{c}\text { Distance } \\
(\mathrm{cm})\end{array}$ & $\begin{array}{c}\text { Peak } j_{+} \\
\left(\mathrm{A} / \mathrm{cm}^{2}\right)\end{array}$ & $\begin{array}{c}\text { Average diameter } \\
(\mathrm{cm})\end{array}$ \\
\hline Mesh & 0 & 9.16 & 4.8 \\
WP & 13.7 & 4.20 & 7.1 \\
\hline
\end{tabular}

Figur. 1. One-dimensional autoneutralization model formulated by Humphries $c t a l^{1}{ }^{1}$ on which this experiment is based. When a proton space charge having multi-MeV kinetic energy erupts through a thin ground plane, it can extract a compensating electron charge and current density and produce a neutral moving proton-electron plasma with a positive space potantial above ground.

Figure 2. Curve 1: WP data. Curve 2: current-density $j_{+}$time history of the driving proton pulse at the floating WP location. Curve 3: kinetic-energy $E_{K}$ time history at the same location. Curve 4: Electronemission signal enhancement added to curve 3 .

Figure 3. (a) End view of the stainless steel drift tube toward the entrance collimator. This perspective shows the alignment of the mesh and the WP. (b) Side view showing the relative locations of the WP, mesh, and coliimator.

Figure 4. Wire probe, consisting of a brass rod extending into the plasma from a ceramic high-voltage insulator and low-inductance resistor chain. 


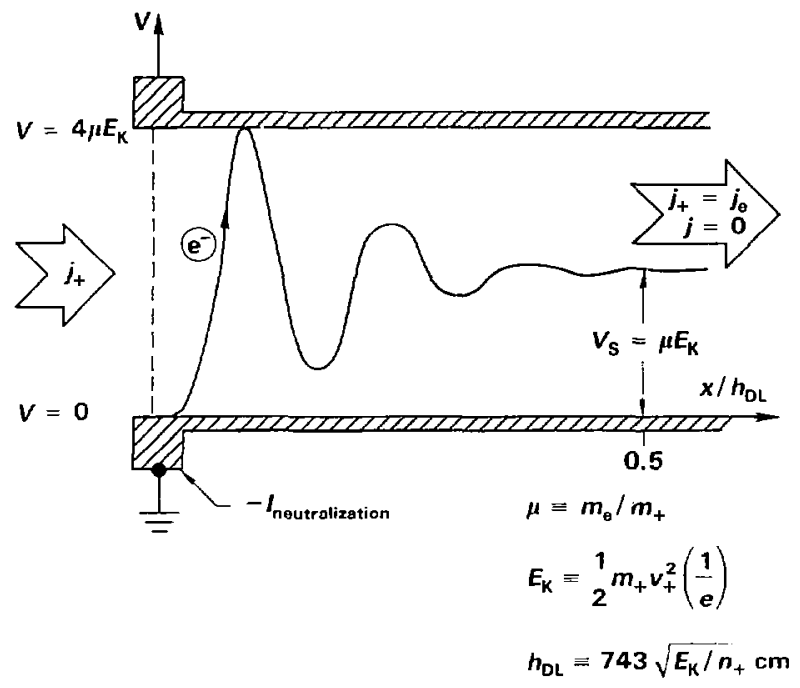

FIG. 1

9 


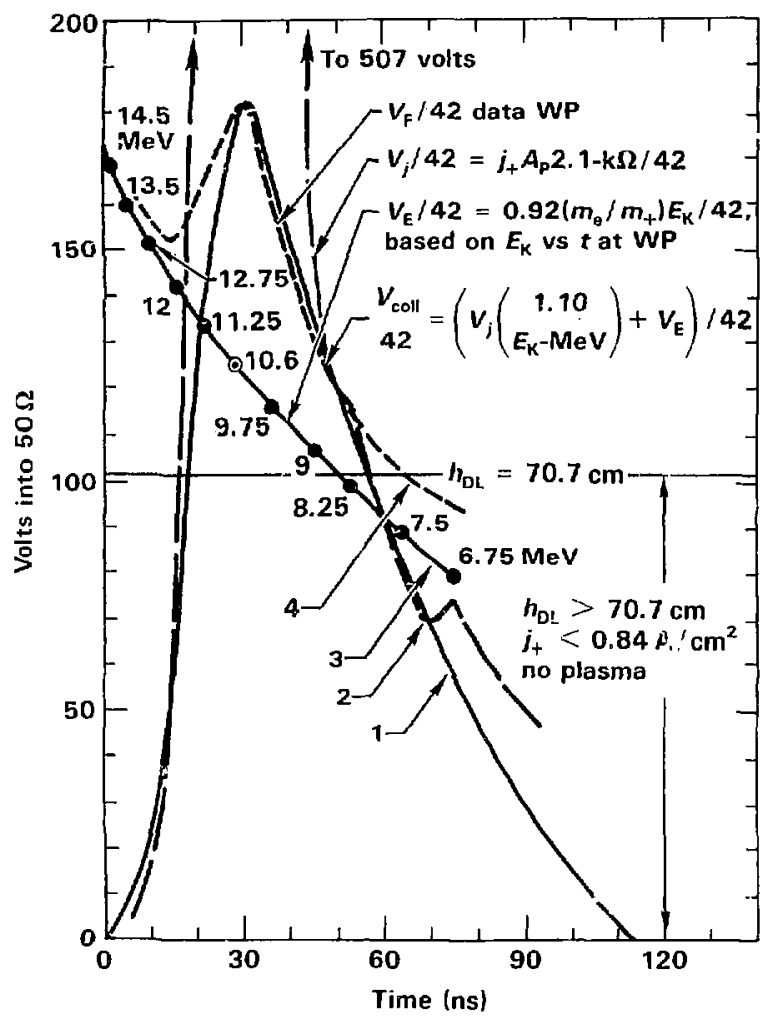

FIC. 2 


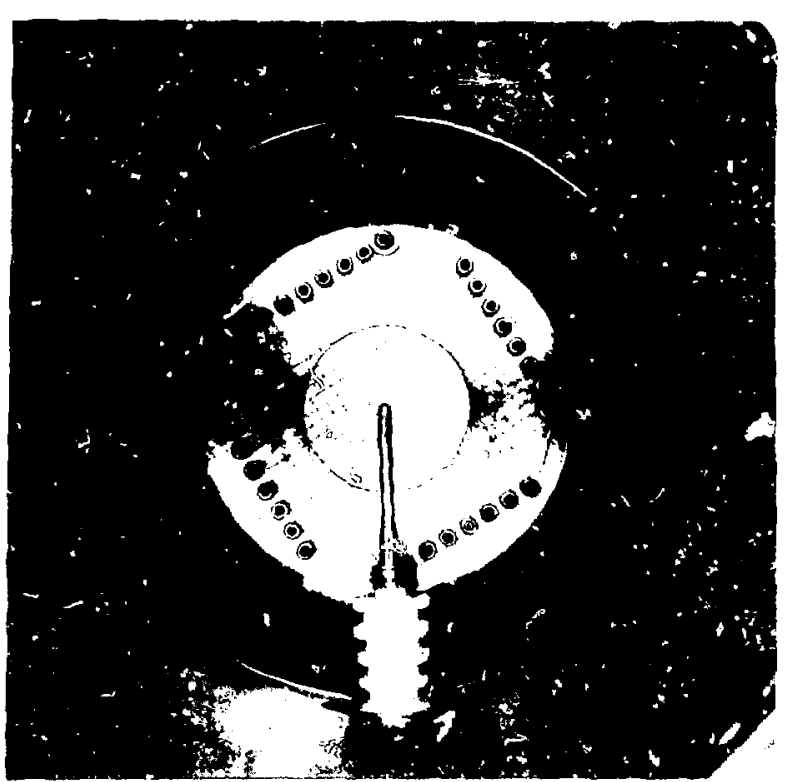

(a)

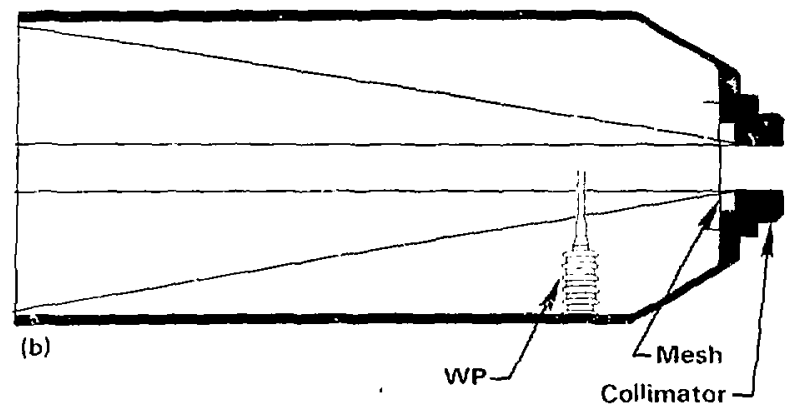

FIG. 3 


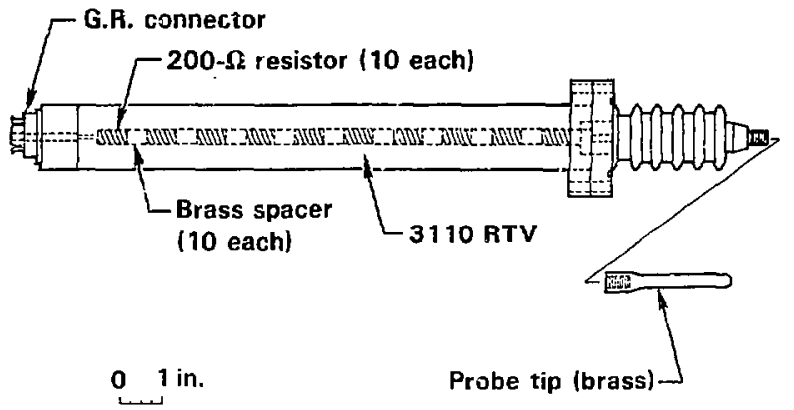

F.G. 4 